\title{
Waders (Scolopacidae) surviving despite malaligned leg fractures in the wild: kinematics of bipedal locomotion
}

\author{
Jessica Reichert ${ }^{1}$, Gerald Mayr ${ }^{2}$, Thomas Wilke ${ }^{1}$ and Winfried S. Peters ${ }^{3^{*}}$
}

\begin{abstract}
Background: Bone fracture frequencies and survival rates are essential parameters in skeleton evolution, but information on the functional consequences of naturally healed fractures is scarce. No leg bone fracture healing in the wild has been reported so far from long-legged Charadriiformes (waders), which depend on bipedal locomotion for feeding.

Methods: We documented a healed but malaligned tarsometatarsus fracture in a wild Willet (Tringa [Catoptrophorus] semipalmata), and a malaligned tibiotarsus fracture in a Curlew (Numenius arquata) skeleton from a museum collection. Functional consequences of the malalignments were evaluated by kinematic analyses of videos (Willet) and in silico 3D modeling (Curlew).

Results: The Willet's left tarsometatarsus exhibited an angular malalignment of $70^{\circ}$, resulting in a limping gait that was less pronounced at high than at low walking speed. The bird seemed unable to club the toes of the left foot together, apparently a secondary effect of the deformity. The Curlew's tibiotarsus showed an angular and an axial malalignment, causing the foot to rotate outwards when the intertarsal joint was flexed. Despite the severe effects of their injuries, the birds had survived at least long enough for the fractures to heal completely.

Conclusions: Somewhat unexpectedly, leg fractures are not necessarily fatal in long-legged waders, even if deformities occur in the healing process. Bipedal locomotion on vegetated grounds must have been impeded due to the bone malalignments in both analyzed cases. The birds probably alleviated the impact of their handicaps by shifting a larger proportion of their activities to vegetation-free habitats.
\end{abstract}

Keywords: 3D modeling, Bone fracture healing, Tringa (Catoptrophorus) semipalmata, Kinematic gait analysis, Long bone malalignment, Numenius arquata, Scolopacidae

\section{Background}

Vertebrates invest material and energy to build and maintain skeletons. From an evolutionary viewpoint, skeletons should be as economic as possible to minimize these costs, but weaker skeletal material is more susceptible to catastrophic failure. Rigorous tests of hypotheses concerning the balance between the resulting selective forces (Alexander 1984, 1997) have proven difficult, mainly due to the scarcity of reliable data concerning the natural

\footnotetext{
*Correspondence: petersw@ipfw.edu

${ }^{3}$ School of Biological Science, Washington State University, Pullman, WA 99164, USA

Full list of author information is available at the end of the article
}

frequencies of bone fractures, survival rates, and the performance of organs after fracture healing.

Goodman and Glynn (1988) detected healed long bone fractures in $0.8 \%$ of 1025 birds of over 240 species collected in Paraguay. A much higher frequency was found in ducks, gulls, and pigeons in Britain; healed fractures were detected in $0.4 \%$ of the 11,095 long bones (femur, tibiotarsus, tarsometatarsus, humerus, radius, ulna) examined, suggesting that $4-5 \%$ of the birds had survived long bone fractures (Brandwood et al. 1986). Even higher rates have been reported in taxonomically more restricted studies. In a sample of 17 vultures (Gyps spp.), three individuals $(18 \%)$ showed healed fractures of the 
ulna (only wings were examined; Houston 1993), and 9\% of 91 urban Blackbirds (Turdus merula) had healed long bone fractures (Lidauer 1983). The wide variance of these frequencies $(0.8-18 \%)$ may be explained partly by the different habitats from which samples were taken (Lidauer 1983; Goodman and Glynn 1988). But even in the best case, the frequency of healed bone fractures in a population remains an inherently equivocal parameter: an observed frequency of healed fractures may result from a similar frequency of fracture events linked with a high survival rate, or a (much) higher fracture frequency linked with high lethality.

This impasse could be overcome if a complementary body of field observations of fracture events and healing processes were available. There are reports of individual birds surviving long bone fractures in the ornithological (Wood 1941; Abbott 1943; Dillon 1961), archaeological (Parmalee 1977; Serjeantson 2009; Atherton et al. 2012), and paleontological (Lambrecht 1933; Tasnádi-Kubacska 1962; Mlíkovský and Lukáš 1991) literature. This evidence mostly has anecdotal character, whereas analyses of the effects of healed fractures on limb performance are lacking. Pathological deformities of healed leg bones have been documented repeatedly (Tiemeier 1941; Wood 1941; Atherton et al. 2012). This is not surprising, as the immobilization of bone fragments by surrounding tissues promotes well-aligned fracture healing (Bennett and Kuzma 1992; Tully 2002); the long bones of legs lack such mechanical support. Functional consequences of the reported malalignments have not been evaluated, which is regrettable as bone fractures decrease an individual's fitness not only if the injury is fatal, but also if the performance of the repaired limb is reduced.

Here we describe the first two cases of healed but malaligned leg bone fractures in long-legged waders (Charadriiformes: Scolopacidae), which depend on bipedal locomotion for food acquisition. The types of evidence in the two cases were distinct. One bird was filmed in the wild but not captured, while the other was a skeleton in a museum collection. Nonetheless, biomechanic consequences of the malalignments for the kinematics of bipedal locomotion could be characterized in both cases through appropriate methodologies.

\section{Methods}

\section{Willet}

Willets (Tringa [Catoptrophorus] semipalmata Gmelin; Charadriiformes: Scolopacidae) were filmed (30 frames/s) on Padre Island, Texas, USA $\left(27^{\circ} 26^{\prime} \mathrm{N}, 97^{\circ} 18^{\prime} \mathrm{W}\right)$, on 4 September 2011 (Panasonic DMC-FZ30 camera with DMW-LT55 $1.7 \times$ teleconverter). Frames were extracted (QuickTimePro 7; www.apple.com/quicktime) from sequences showing animals moving perpendicularly to the viewing direction. Using objects in the birds' paths as reference points, the horizontal trajectories of each foot (tarsometatarso-phalangeal joint) and of the estimated center of mass (CM; $2 \mathrm{~cm}$ rostral of the center of the trunk, defined by individual coverts visible in all frames) were determined manually using ImageJ v1.45s (imagej. nih.gov/ij). In the following, we compared slow bipedal locomotion at $<0.5 \mathrm{~m} / \mathrm{s}$ ('walking') with fast locomotion at $>0.9 \mathrm{~m} / \mathrm{s}$ ('running'). Vertical displacements were not estimated since no unambiguous reference points for elevation above ground were available. CM speed was calculated numerically as the slope of the CM trajectory. Angular flexion of the intertarsal joints (ITJ) was measured with ImageJ.

\section{Curlew}

3D scans of tibiotarsi (one malaligned) and tarsometatarsi of a Curlew (Numenius arquata L.; Charadriiformes: Scolopacidae; collected in Essex, UK, 1985; specimen SMF 499, Senckenberg Research Institute, Frankfurt/Main, Germany) were produced with an Artec Spider scanner and processed with Artec Studio v9.2.3.15 (Artec Group, Luxemburg; compare Reichert et al. 2016). This portable scanner proved particularly user-friendly as it does not require external structured light sources or laser illumination. Each bone was scanned from two opposite sides and each pair of scans was aligned using the software's Rigid Alignment tool. 3D models were computed by Fine Serial Registration, Global Registration (min. distance 10, 100 iterations) and Sharp Fusion (resolution 0.2; fill holes by radius, max. radius 5). For visualization, models exported as OBJ-files were transferred to Blender v2.6 (www.blender.org/features/2-73/). To directly compare the injured and healthy legs, bones of the handicapped right leg were mirrored over the midsagittal plane. ITJ flexion was animated using single bone armatures and exported as video files.

\section{Results \\ Willet}

A Willet in the adult non-breeding plumage with malaligned left tarsometatarsus was observed on a sandy beach on Padre Island for $2 \mathrm{~h}$ before it took off and was not seen again (Fig. 1). Other Willets were present but did not congregate. Except for the limping gait (Additional file 1: Video S1), the handicapped bird behaved normally. Short periods of rest $(<12 \mathrm{~min})$ on the dry upper beach alternated with foraging bouts on the lower beach, where the bird often waded in belly-deep water (Fig. 1a). The flight distance did not differ from that of its conspecifics; when walkers approached to about $15 \mathrm{~m}$, the handicapped bird fled running at a speed similar to that of other Willets. When the disturbance persisted, the 

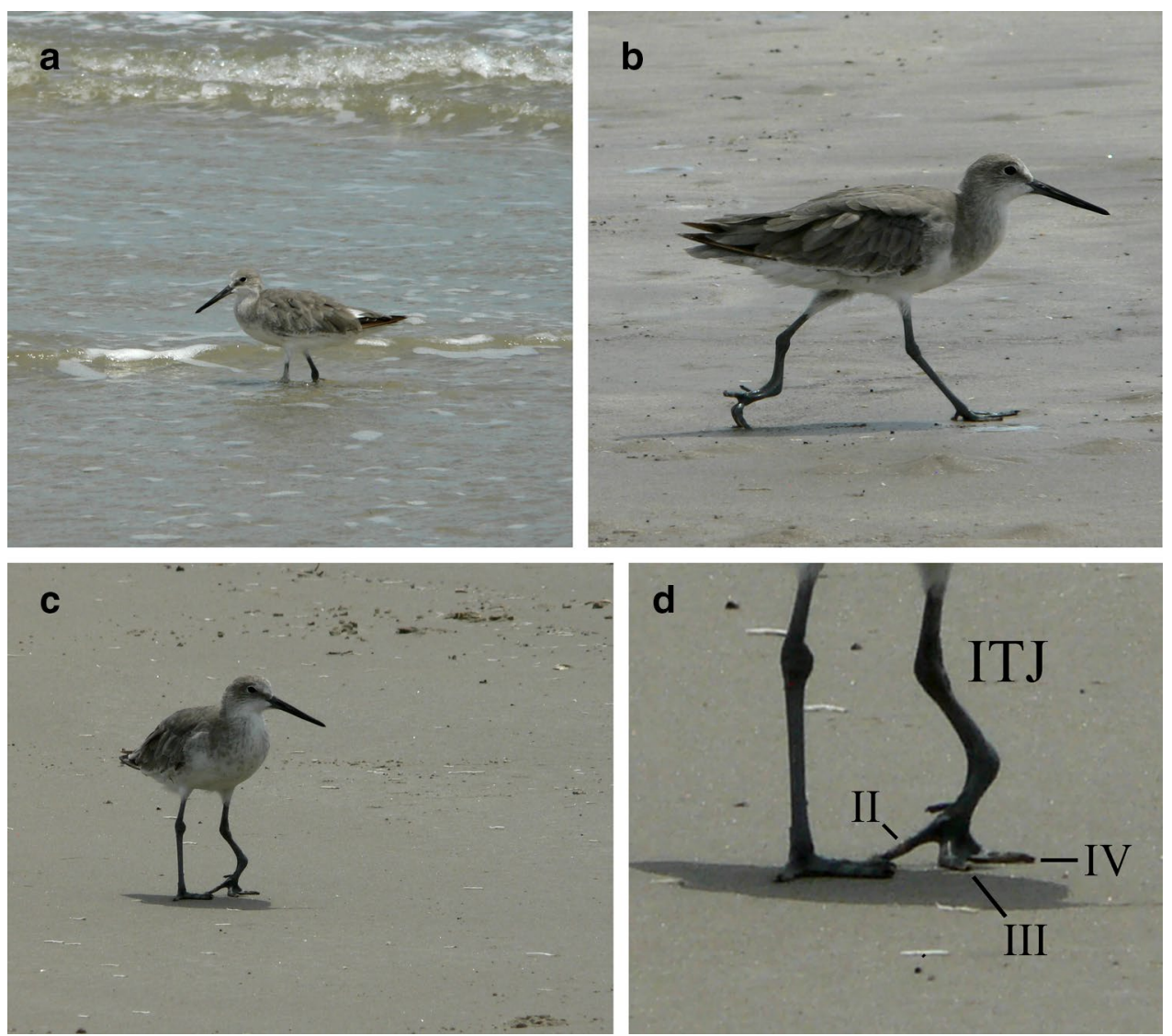

Fig. 1 Willet with malaligned left tarsometatarsus foraging in water (a) and running on the beach (b). When the animal stood on both legs (c), the left toes II, III, and IV contacted the substrate only partly, and the left intertarsal joint (ITJ) was flexed more strongly than the right one (d). Compare Additional file 1: Video S1

bird eventually took off, flew a short distance, and landed without apparent difficulties.

The rather inconspicuous behavior contrasted with the severity of the morphological abnormalities. The distal third of the left tarsometatarsus was sharply bent caudally by $70^{\circ}$ (Fig. 1b). The functional length of the malaligned bone (distance between adjacent joints) was $77 \%$ of that of the healthy tarsometatarsus. Nonetheless, the bird at rest stood firmly on both feet (Fig. 1c), but the intertarsal joint (ITJ) was flexed more strongly in the injured leg (Fig. 1d). The modified posture affected the three forward-facing toes. At the joints between their first and second digits, the third and fourth toes were bent dorsally so that only their distal parts contacted the ground (Fig. 1d). The second toe was held straight, touching the substrate with its tip only. The posture of the toes did not change visibly when the foot was in the air (Additional file 1: Video S1), suggesting restricted toe joint mobility. In contrast, the toes of the healthy foot clubbed together and bent backwards during the leg's swing phase, as in healthy willets (not shown).
Willets increased walking speed by making longer strides in faster succession (Fig. 2 shows representative gait kinematics of a healthy animal at 0.38 and $1.21 \mathrm{~m} / \mathrm{s}$ ). This was true also for the handicapped Willet, which moving at 0.25 and $1.20 \mathrm{~m} / \mathrm{s}$ showed stride lengths (distance between successive contact points of one foot) of 20.5 and $36.8 \mathrm{~cm}$, respectively, and step cycle frequencies of 1.2 and 3.2 per second, respectively (Fig. 3a, c). Healthy Willets decreased the duty factor (proportion of time a foot has contact with the ground) with increasing speed (Fig. 2b, d). The healthy right foot of the handicapped Willet showed this decrease in duty factor at higher speed as well, while the duty factor of the injured foot was similar in the two speeds analyzed (Fig. 3b, d).

Right and left step lengths (distance between the initial contact of one foot and the initial contact of the opposite foot) were equal in healthy Willets regardless of speed, so that the step-size ratio was 1 (Fig. 2a, c). The duty factors were similar in both feet (Fig. 2b, d). The speed of the estimated center of mass (CM) showed small-amplitude oscillations with maxima occurring when one foot 

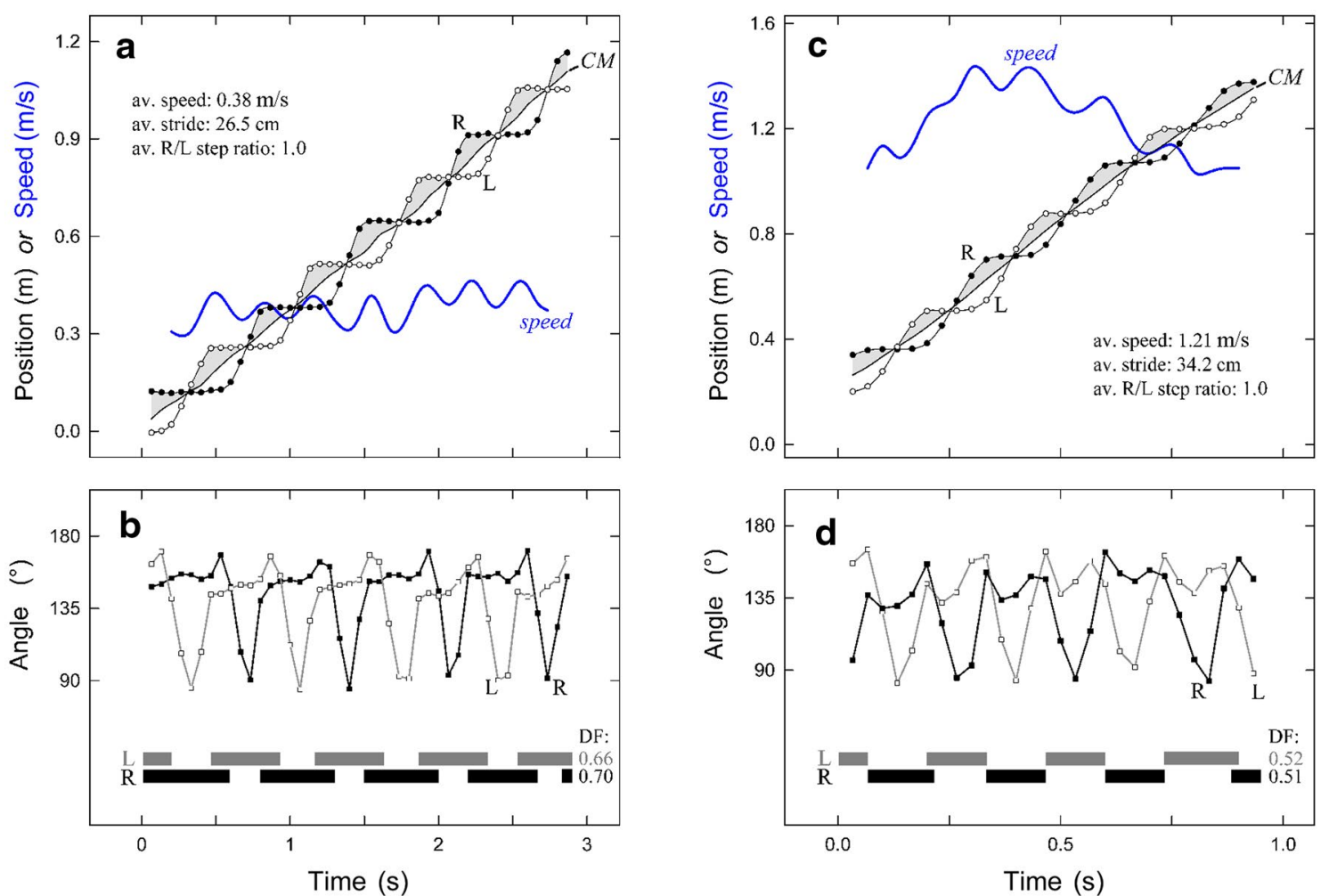

Fig. 2 Kinematic gait analysis of a healthy Willet, based on videos taken at 30 frames/s. Representative step cycles are presented for the walking $(0.38 \mathrm{~m} / \mathrm{s} ; \mathbf{a}, \mathbf{b})$ and the running animal $(1.21 \mathrm{~m} / \mathrm{s} ; \mathbf{c}, \mathbf{d}) . \operatorname{In}(\mathbf{a})$ and $(\mathbf{c})$, positions of the left and right foot (tarsometatarso-phalangeal joint) are given as open and closed circles, respectively. A black line indicates the trajectory of the bird's estimated center of mass (CM); for clarity, areas representing a foot positioned in front of the CM are shaded. CM speed is shown in blue. Average speed, stride length, and the ratio between the lengths of right and left steps are listed. In (b) and (d), the corresponding intertarsal joint angles (top), the stance phases (bottom) of the right ( $R$; black) and left ( $L$; grey) leg, and the right and left duty factors (DF) are shown

entered the swing phase while the other entered the stance phase (Fig. 2a, c). In the walking $(0.25 \mathrm{~m} / \mathrm{s})$ handicapped Willet, right steps were 2.5 times longer than left steps, and CM speed oscillated strongly with peaks at the end of the swing phase of the healthy leg only (Fig. 3a). In the malformed left leg, the duty factor was significantly lower compared to the healthy right leg (Fig. 3b). The differences between the legs were less pronounced when the animal was running $(1.2 \mathrm{~m} / \mathrm{s})$, as the duty factors became similar in both legs (Fig. 3d), right steps were only $30 \%$ longer than left steps, and CM speed showed alternating large and small maxima that coincided with the start of the swing phases of the left and right leg, respectively (Fig. 3c).

Healthy Willets at high speed exhibited an ITJ flexion angle minimum of about $90^{\circ}$ during the swing phase and a less pronounced secondary minimum of $130^{\circ}-140^{\circ}$ in the stance phase (Fig. 2d). At lower speed, the secondary minimum tended to disappear, and the proportion of the step cycle during which the ITJ was strongly flexed decreased, as expected since this flexion corresponded to the swing phase (Fig. 2b). In the handicapped Willet at high speed, the ITJ of the injured leg was flexed more strongly by about $20^{\circ}$ than the ITJ of the healthy leg in the corresponding phases (Fig. 3d); otherwise, the cycles resembled those of healthy birds. At low speed, the healthy leg showed a relatively shortened ITJ flexion phase and no relative minimum in the stance phase (Fig. 3b), similarly as in healthy birds (Fig. 2b). In contrast, the extended and flexed phases were of similar duration in the injured leg.

\section{Curlew}

Motivated by our above observations, we searched the Senckenberg collection for healed leg bone fractures in the skeletons of long-legged Scolopacidae. Among 60 skeletons of Tringa, Numenius, and Limosa, we found one Curlew whose right tibiotarsus showed a malaligned healed fracture about one-third of the total bone length from its distal end (Fig. 4a). The rest of the skeleton was without apparent pathologies. The healed fracture was thickened but consisted of solid bone material with a 

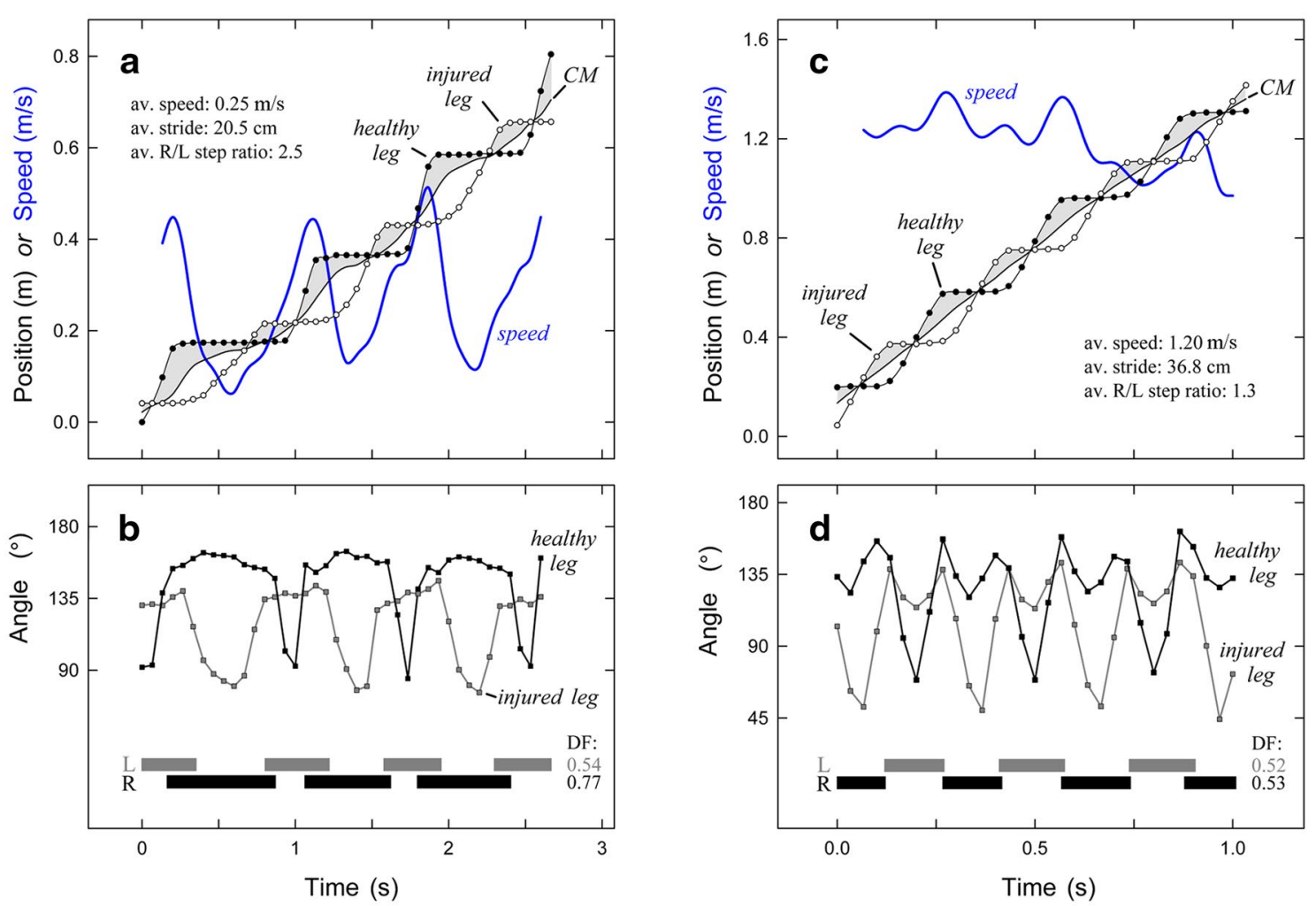

Fig. 3 Kinematic gait analysis of the handicapped Willet. Step cycles are shown for the walking $(0.25 \mathrm{~m} / \mathrm{s} ; \mathbf{a}, \mathbf{b})$ and the running bird (1.20 m/s; $\mathbf{c}$, d): other details as in Fig. 2. The injured leg is the left one

smooth surface. The thickened bone portion was penetrated by a canal of about $1 \mathrm{~mm}$ diameter, which also had a solid inner surface (Fig. 4a).

Direct measurement indicated a reduction of the functional length of the tibiotarsus by $5 \%$ compared to the unaffected leg. For further analyses, in silico models were used (Additional file 3: 3D model S1, Additional file 4: 3D model S2), which enabled manipulations impossible to perform with actual bones such as mirroring and superposition (as seen in Fig. 4b-g). The axis of the malaligned bone was bent medially by about $34^{\circ}$ at the fracture site. The plane of bending (i.e. the plane defined by the three reference points: knee, ITJ, and the kink in the bone) formed an angle of $30^{\circ}$ with the sagittal plane. Thus, the distal parts of the right leg were expected to project inwards into the plane of movement of the left leg, which would have made bipedal locomotion practically impossible. This, however, did not occur as the rotation of the bending plane relative to the sagittal plane was more than balanced by a $\sim 50^{\circ}$ lateral rotation around its long axis of the distal fragment of the malaligned tibiotarsus with respect to the proximal fragment. The ultimate consequence of these geometric changes was a lateral rotation of the plane of ITJ flexion in the right leg by some $40^{\circ}$ relative to the mid-sagittal plane (Fig. 4b-g, Additional file 2: Video S2). Thus, when the ITJ was flexed, the right foot moved lateral, i.e. in an outward direction, from the plane in which ITJ flexion normally occurs.

\section{Discussion}

We analyzed malaligned long bones in the legs of two waders. In the Willet, the behavior of the bird in the wild was documented, and anatomical information had to be derived from photographs. In the Curlew, the anatomy of the malformed bone could be examined and its function modeled, whereas behavioral consequences could only be inferred. Nonetheless, the two sets of information support similar conclusions.

Although the wild Willet's deformed limb could not be examined, a fracture is the most plausible explanation for its anatomical aberration. Following a fracture, the distal bone fragment probably was fixed during the healing process in the observed position by the pull of the tendons that connect the toes to more proximally located muscles. Since these tendons are running mainly along the caudal side of the tarsometatarsus (Stolpe 1932; 


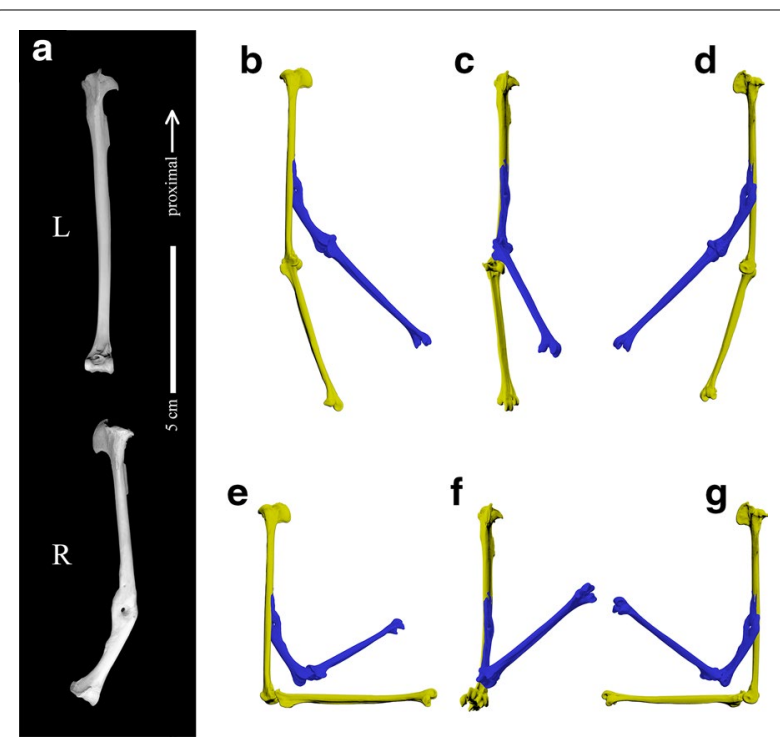

Fig. 4 Effects of a tibiotarsus malalignment on the kinematics of the intertarsal joint (ITJ) in the right leg of a Curlew (SMF 499; Senckenberg Research Institute). a Tibiotarsi of the handicapped bird; cranial view of the normal left $(L)$ and caudo-lateral view of the misaligned right (R) bone that shows the canal through the ossified callus. b-g 3D models of the left (yellow) and right (blue) tibiotarsus and tarsometatarsus, with extended (b-d) or flexed $\left(90^{\circ} ; \mathbf{e}-\mathbf{g}\right)$ ITJ (scale reduced to $65 \%$ of that in $\mathbf{a}$ ). The bones of the malaligned right leg are mirrored (turning them into left leg bones geometrically), and the proximal part of the normal tibiotarsus was superimposed on the malaligned tibiotarsus to directly visualize the geometric effects of the deformity. c, f Cranial views; b, e medial views (from the right); d, $\mathbf{g}$ lateral views (from the left). Compare Additional file 2: Video S2, Additional file 3: 3D model S1 and Additional file 4: 3D model S2

Hudson 1937), they must have exerted asymmetric forces on the leg distal of the fracture. The smoothly rounded rather than sharply kinked caudal surface of the limb at the fracture site supports this idea (Fig. 1b, d). In this interpretation, the anatomical and functional changes observed in the toes appear as secondary responses to the requirements of the modified biomechanic apparatus.

Walking birds accelerate by increasing step cycle frequency and stride length simultaneously (Gatesy and Biewener 1991; Gatesy 1999; Reilly 2000; Abourachid 2001; Rubenson et al. 2004; Nudds et al. 2010; Nyakatura et al. 2012). Since birds increase cycle frequency by shortening the stance phase at constant swing phase, the duty factor decreases with increasing speed. These kinematic characters were evident in healthy Willets, too (Fig. 2a, c). Moreover, the ITJ flexing cycles of Willets (Fig. 2b, d) resembled those reported from other birds (Stoessel and Fischer 2012; Nyakatura et al. 2012). Thus, Willets exhibited typical kinematics of avian bipedal locomotion, and the aberrations in the handicapped individual (Fig. 3) may represent general responses of the biomechanic system 'bipedal bird' to injuries of the type described. The deviations from normal gait kinematics in the handicapped bird were more strongly expressed at low (Fig. 3a, b) than at high (Fig. 3c, d) velocity. Apparently, the bird's momentum at higher speed enabled it to maintain an almost symmetric gait. It would be interesting if case studies of other species became available for comparison.

Willets in the region at the time of observation mostly are winter residents and migrants. Given the handicapped bird's inconspicuous foraging and flight behavior, it appears possible that it was migrating successfully. More severe effects may have been caused by its inability to fold the toes of the handicapped leg during the leg's swing phase. Healthy Willets (not shown) and other Scolopacidae (Wortmann 1972: 281) club the toes together and bend them backwards while the foot is in the air. This appears to prevent entanglements of the feet with objects on the ground (Wortmann 1972: 335). If so, the handicapped Willet's ability to move swiftly on vegetation-covered surfaces probably was compromised (compare Bergman 1946: 20), which may have caused the bird to forage mostly on vegetation-free ground. We observed the bird foraging only on surfaces without vegetation, but, unfortunately, the period of observation was too short to justify general conclusions concerning foraging behavior. On the other hand, spread toes certainly generate more drag than clubbed ones, and wading in water must have been more difficult for the handicapped bird than for its healthy conspecifics-but it did not seem to avoid wading at all (Fig. 1a).

In the case of the Curlew, conclusions concerning the functional and behavioral consequences of the healed injury had to be derived from the structure of the affected bone. The solid bone material at the fracture site indicated secondary bone healing with completed callus ossification (Roggemann 1930; Bennett and Kuzma 1992). Evidently, the bird had lived long enough for the fracture to heal fully. An intriguing feature was the canal that extended through the healed fracture (Fig. 4a). Since the inner surface of this canal consisted of solid bone without opening into the inner bone cavity, we can exclude that it was generated post mortem. The structure could be explained by the loss of a non-viable bone fragment, a frequent result of leg bone trauma in birds (Bennett and Kuzma 1992; Tully et al. 1996).

To evaluate the functionality of the malaligned tibiotarsus, we applied modeling techniques based on optical 3D scanning, which we had optimized for biological applications in unrelated contexts (Reichert et al. 2016, 2017). 3D models in silico possess significant analytical advantages. Models can be more easily aligned precisely with 
defined planes and axes than actual bones, and the measurement of distances, surface areas, volumes, and angles is straightforward. In silico models enable manipulations that are impossible with real objects, including mirroring over freely defined planes and the superposition of objects in space (compare Fig. 4). We used 3D models to visualize the combined results of the two main geometric features of the deformed tibiotarsus, namely the angular malalignment characterized by the plane of bending of the kink in the bone, and the rotational malalignment of the distal tibiotarsus fragment (Fig. 4; Additional file 2: Video S2). Our analysis showed that the right foot moved outward, away from the mid-sagittal plane, every time the bird flexed its right ITJ to make a step. This must have impeded bipedal locomotion in dense vegetation. However, in the living Curlew the effect may have been balanced partially by long-axis rotation of the femur and/or tibiotarsus, a frequently overlooked type of movement (Kambic et al. 2014). Unfortunately, we lack the necessary information to evaluate this possibility quantitatively.

\section{Conclusions}

The unexpected observations of healed but malaligned leg bones in two wader species that depend on terrestrial locomotion for food acquisition demonstrates that leg fractures are not necessarily fatal in these animals, even if severe deformities occur. The severe angular malalignment of the Willet's tarsometatarsus caused a limping gait most pronounced at low walking speed and an inability to club the toes of the affected leg together. The combined angular and axial malalignment of the Curlew's tibiotarsus caused a lateral rotation of the foot when it was lifted. In both cases, a reduced ability to move swiftly through dense vegetation was inferred. Both species utilize vegetated ground, particularly during the breeding season, but also forage on flat surfaces devoid of vegetation, such as mud flats and beaches. It seems plausible that the handicapped birds minimized the impact of their deformities by shifting an even higher proportion of their activities to vegetation-free habitats.

While the nature of the available evidence was distinct for the Willet and the Curlew, insights into the effects of the injuries on locomotory kinematics were gained in both birds through relatively simple, inexpensive methods-kinematic analysis of videos taken with standard digital cameras of animals in the wild, and optical 3D scanning followed by in silico modeling of affected bones. The routine application of these methods to similar cases will augment our knowledge base of non-lethal bone fractures in the wild, which can be expected to promote our understanding of skeleton evolution (Alexander 1984).

\section{Additional files}

Additional file 1: Video S1. Video-clip (.mov format) of a Willet with malaligned left tarsometatarsus walking and running on a beach on Padre Island, Texas, USA.

Additional file 2: Video S2. Video-clip (.mov format) showing the kinematics of intertarsal joints in the healthy and malaligned leg of a Curlew.

Additional file 3: 3D model S1. 3D models of the tibiotarsus and tarsometatarsus of the healthy left and the malaligned right leg of a Curlew with expanded intertarsal joint. The right leg is mirrored to facilitate direct comparison of the two legs. The models are in the polygon file format (.ply) and can be displayed by standard software such as the free, open source MeshLab (meshlab.sourceforge.net/).

Additional file 4: 3D model S2. As 3D model S1, but with flexed intertarsal joint.

\section{Authors' contributions}

JR scanned the curlew bones, which had been discovered in the Senckenberg collection by GM, and performed the 3D modeling. WSP filmed the willet, analyzed its gait kinematics, coordinated this research, and drafted the manuscript, which was discussed, improved, and finalized by all authors. All authors read and approved the final manuscript.

\section{Author details \\ ${ }^{1}$ Department of Animal Ecology and Systematics, Justus Liebig University, Heinrich-Buff-Ring 26-32 (IFZ), 35392 Giessen, Germany. ${ }^{2}$ Ornithology Section, Senckenberg Research Institute and Natural History Museum, Senckenbergan- lage 25, 60325 Frankfurt, Germany. ${ }^{3}$ School of Biological Science, Washington State University, Pullman, WA 99164, USA.}

\section{Competing interests}

The authors declare that they have no competing interests.

\section{Availability of data and materials}

All data generated and/or analyzed during this study are included in this published article and its supplementary information files.

Received: 13 June 2017 Accepted: 30 August 2017

Published online: 04 September 2017

\section{References}

Abbott CE. Bone repair in ducks. Auk. 1943;60:447 (plus Plate 12).

Abourachid A. Kinematic parameters of terrestrial locomotion in cursorial (ratites), swimming (ducks), and striding birds (quail and guinea fowl). Comp Biochem Physiol A. 2001;131:113-9.

Alexander RM. Optimum strengths for bones liable to fatigue and accidental fracture. J Theor Biol. 1984;109:621-36.

Alexander RM. A theory of mixed chains applied to safety factors in biological systems. J Theor Biol. 1997;184:247-52.

Atherton S, Brothwell D, David R, McKnight L. A healed femoral fracture of Threkiornis aethiopicus (Sacred Ibis) from the animal cemetery at Abydos, Egypt. Int J Paleopathol. 2012;2:45-7.

Bennett RA, Kuzma AB. Fracture management in birds. J Zoo Wildl Med. 1992;23:5-38.

Bergman G. Der Steinwälzer, Arenaria i. interpres (L.), in seiner Beziehung zur Umwelt. Acta Zool Fennica. 1946;47:1-151.

Brandwood A, Jayes AS, Alexander RM. Incidence of healed fracture in the skeletons of birds, molluscs and primates. J Zool Lond. 1986;208:55-62.

Dillon OW. Recovery of a crippled Gadwall. Auk. 1961;78:273-4.

Gatesy SM. Guineafowl hind limb function. I: cineradiographic analysis and speed effects. J Morphol. 1999;240:115-25. 
Gatesy SM, Biewener AA. Bipedal locomotion: effects of speed, size and limb posture in birds and humans. J Zool Lond. 1991;224:127-47.

Goodman SM, Glynn C. Comparative rates of natural osteological disorders in a collection of Paraguayan birds. J Zool Lond. 1988;214:167-77.

Houston DC. The incidence of healed fractures to wing bones of White-backed and Rüppell's Griffon vultures (Gyps africanus and G. rueppelli) and other birds. Ibis. 1993;135:468-75.

Hudson GE. Studies on the muscles of the pelvic appendage in birds. Am Midl Nat. 1937;18:1-108.

Kambic RE, Roberts TJ, Gatesy SM. Long-axis rotation: a missing degree of freedom in avian bipedal locomotion. J Exp Biol. 2014;217:2770-82.

Lambrecht K. Handbuch der Palaeornithologie. Berlin: Gebrüder Borntraeger; 1933

Lidauer RM. Knochenfrakturen bei Stadtamseln (Turdus merula). Ökol Vögel. 1983:5:111-26.

Mlíkovský J, Lukáš J. Osteological disorders in late Pleistocene birds from the Schusterlucke, Lower Austria. Ann Nat Mus Wien. 1991;92:101-3.

Nudds RL, Gardiner JD, Tickle PG, Codd JR. Energetics and kinematics of walking in the barnacle goose (Branta leucopsis). Comp Biochem Physiol A. 2010;156:318-24.

Nyakatura JA, Andrada E, Grimm N, Weise H, Fischer MS. Kinematics and center of mass mechanics during terrestrial locomotion in northern Lapwings (Vanellus vanellus, Charadriiformes). J Exp Zool. 2012;317A:580-94.

Parmalee PW. Avian bone pathologies from Arikara sites in South Dakota. Wilson Bull. 1977;89:628-32.

Reichert J, Schellenberg J, Schubert P, Wilke T. 3D scanning as a highly precise, reproducible, and minimally invasive method for surface area and volume measurements of scleractinian corals. Limnol Oceanogr Methods. 2016;14:518-26
Reichert J, Backes AR, Schubert P, Wilke T. The power of 3D fractal dimensions for comparative shape and structural complexity analyses of irregularly shaped organisms. Methods Ecol Evol. 2017. doi:10.1111/2041-210X.12829.

Reilly SM. Locomotion in the quail (Coturnix japonica): the kinematics of walking and increasing speed. J Morphol. 2000;243:173-85.

Roggemann H. Untersuchungen über die Heilung von Knochenbrüchen be Vögeln. Zeitschr Wiss Zool. 1930;137:627-86.

Rubenson J, Heliams DB, Lloyd DG, Fournier PA. Gait selection in the ostrich: mechanical and metabolic characteristics of walking and running with and without an aerial phase. Proc R Soc Lond B. 2004:271:1091-9.

Serjeantson D. Birds. Cambridge: Cambridge University Press; 2009.

Stoessel A, Fischer MS. Comparative intralimb coordination in avian bipedal locomotion. J Exp Biol. 2012;215:4055-69.

Stolpe M. Physiologisch-anatomische Untersuchungen über die hintere Extremität der Vögel. J Ornithol. 1932;80:161-247.

Tasnádi-Kubacska A. Paläopathologie. Pathologie der vorzeitlichen Tiere. Jena: Gustav Fischer Verlag; 1962.

Tiemeier OW. Repaired bone injuries in birds. Auk. 1941;58:350-9.

Tully TN. Basic avian bone growth and healing. Vet Clin N Am Exotic Anim Pract. 2002;5:23-30.

Tully TN, Martin GS, Haynes PF, Cornick-Seahorn J, Pechman RD. Tarsometatarsal sequestration in an Emu (Dromaius novaehollandiae) and an Ostrich (Struthio camelus). J Zoo Wildl Med. 1996;27:550-6.

Wood HB. Fractures among birds. Bird Band. 1941;12:68-72.

Wortmann B. Zur biologischen Anatomie der Hinterextremität von Limikolen. Zeitschr Wiss Zool. 1972:183:253-349.

\section{Submit your next manuscript to BioMed Central and we will help you at every step:}

- We accept pre-submission inquiries

- Our selector tool helps you to find the most relevant journal

- We provide round the clock customer support

- Convenient online submission

- Thorough peer review

- Inclusion in PubMed and all major indexing services

- Maximum visibility for your research

Submit your manuscript at www.biomedcentral.com/submit
() Biomed Central 